\title{
STOCHASTIC MODEL OF SHORT-TERM PREDICTION OF STOCK PRICES AND ITS PROFITABILITY IN THE CZECH STOCK MARKET
}

\section{Milan Svoboda}

\section{Introduction}

One of the characteristics of stock markets is their permanent fluctuation. Periods of share price growth alternate with periods of share price decrease, both of different lengths. One of the possibilities applied for prediction of share price development and for simulation of this fluctuation is technical analysis (TA).

Principles and methods of TA are widely described, for example by Murphy (1999). TA is understood as an extensive complex of methods which predict the future prices from the previous prices and trade volumes. The basis of TA can be summarized by the following three statements:

- The share price is determined only by mutual iteration between supply and demand. Supply and demand are influenced by fundamental and psychological factors.

- Share rates move in trends which have certain inertia. A trend change is caused by a change of ratio between the selling and buying (optimistic and pessimistic investors). These trend changes are possible to be identified in time by studying historical prices and trade volumes. Technical analysts distinguish three types of trends. A primary trend which lasts from one year to several years, a secondary trend which lasts for several months and a minor trend which lasts for days or weeks.

- Development cycles and formations repeat themselves. It is based on the human nature to behave in a similar way under the same circumstances. This fact allows predicting the future rate development.

The basic assumption for technical analysts is the second statement. Identifying trend in time raises hope of an above-average profit. The main goal for technical analysts nowadays is to predict short term price movements, while important being not the price level but the price changes estimate. TA proceeds from some scientific theories but above all it is based on a great amount of empirical findings. On the base of these empirical findings particular methods, whose number is practically unlimited, are created.

It is necessary to mention that academicians, in contrast to businessmen, did not trust TA for a long time. The reason was the Efficient Market Hypothesis according to which markets perform a random walk and therefore they are unpredictable. An effective market is thought to be such market which reacts to all new information immediately. This information cannot be predicted, it comes randomly and thus a price change is also random. It is not possible to reach above-average profit in effective markets and according to this theory TA methods are non-functional. The idea of 'random walk' was first published probably by the French mathematician L. Bachalier. This theory was later developed and with empirical studies supported by Fama $(1965 ; 1970)$. The conclusions of Fama were confirmed in the paper by Solnik (1973), for example. There were also some previous and widely cited negative empirical studies about a reliability of TA in stock markets, for example Fama and Blume (1966) or Jensen and Benington (1970). However, other later papers, for example Sweeny (1988) or Brock et al. (1992) prove that business strategies using TA methods are able to overcome a passive share holding strategy called "buy and hold" and to overcome the market. Since the computing capacity became cheaper and electronical databases developed and are easily accessible, the number of studies exploring the profitability of different TA methods has been growing.

The goal of this empirical research is to create a stochastic model which would predict a short term share price movement successfully. 
It means that a model will be usable for generating business signals and that trading according to these signals will bring higher profit than passive share holding. We proceed from the TA assumption that a share price moves in short term trends and during that trend the share price accumulates a certain profit or a loss in relation to the price at the beginning of the trend. We also assume that the probability of this trend change grows with an increasing accumulated loss or profit. The crucial question for us is how big the accumulated loss or profit must be to cause a trend change with a high probability. Considering the data character (daily opening and closing prices) we will use the Markov chains theory for modelling the trend change probability.

The structure of the paper is as follows. The first part is dedicated to the Markov chains theory to a sufficient extent and also to already published works which use Markov chains for the prediction of stock markets. The second part characterises data on which the research is lead and describes the methodology of the research. The third part is dedicated to empirical findings and there is also a brief discussion about them included. The closing part presents an evaluation and also indicates where the following research is oriented.

\section{Theoretical Background}

Markov chains (MC) are used for modelling processes which can be found in one of finite (countable) number of states in discrete time moments. $\mathrm{MC}$ is understood as a sequence of discrete random variables $X_{1}, X_{2}, X_{3}, \ldots$. with the Markov property which can be formally described as follows:

$$
\begin{aligned}
& P\left(X_{n+1}=x_{n+1} \mid X_{1}=x_{1}, X_{2}=\right. \\
& \left.=x_{2}, \ldots \ldots . X_{n}=x_{n}\right)=P\left(X_{n+1}=\right. \\
& \left.=x \mid X_{n}=x_{n}\right)
\end{aligned}
$$

In other words, MC is a random process with a discrete set of states, discrete time and of that kind that the probability $p_{i}(n)$, that at the time moment $t_{n}$ the process will be in state $i$, is stochastically dependent only on the state at the previous time moment, i.e. on the state at the time $t_{n-1}$. Particular realizations $x_{i}$ are elements of a countable set $S=\left\{s_{i}\right\}, i=1,2, \ldots$, $N$ which is called a state space. Behaviour of the described process is determined by:

- vector of unconditional probabilities $p(n)^{\top}=\left[p_{1}(n), p_{2}(n), \ldots \ldots, p_{N}(n)\right]$, where T means transposition. For $n=0,1,2, \ldots p_{i}(n)$ denotes probability that the process is in the moment $n$ in the state $i$,

- transition probability matrix $\mathbf{P}$ whose elements $p_{\mathrm{ij}}$ give conditional probability of process transition from the state $i$ to the state $j$. That could be formally described $p_{\mathrm{ij}}=P\left(X_{n}=\mathrm{s}_{\mathrm{j}} \mid \mathrm{X}_{\mathrm{n}-1}=\mathrm{s}_{\mathrm{i}}\right)$, where $i=1,2, . . N$ and $j=1,2, \ldots N$ and where $p_{i j}$ can depend on $n$. In case that $p_{i j}$ does not depend on $n$ at all, we speak about homogenous MC, in the opposite case we speak about nonhomogenous MC.

If we know the probability of particular states appearance at the time moment when the process starts, we can describe the process behaviour using the following relations:

$$
p^{T}(n)=p^{T}(n-1) \mathbf{P} \text { thus } p^{T}(n)=p^{T}(0) \mathbf{P}^{n}
$$

The first task will be to find an appropriate principle for defining a state space. We need to have such a state space model where there are states from which the process will most likely proceed into states with an opposite trend. In other words, we need to find such states in which a trend change will occur with high probability. Such states would be usable for generating buying and selling orders.

Application of MC for stochastic description of stock markets development and prediction of their development is used very rarely. For example, the works Zhang and Zhang (2009), Doubleday and Esunge (2011) and Vasanthi et al. (2011) deal with stock markets modelling using the MC theory. A common feature of these papers is that they describe a state space very shortly. A state space is defined on the base of a size of a daily share price change or share index. The results found out on such defined state space do not offer a possibility of a suitable application.

More approaches to a state space definition are offered in the work Svoboda and Lukáš (2012). In this paper three ways of state space defining are described. The first approach is the same as in the above mentioned works and a state space is defined according to a size of a daily share price change expressed as percentage. The second approach defines 
a state space also according to daily share price changes but the interval span for space assignment is set as a multiple of a standard deviation of daily share price changes. That implies that each share has its individually defined state space. Neither the first nor the second approach seems to be the suitable one for our goals and does not offer states with high trend change probability. Only the third approach seems to be the suitable one. It defines a state space on the basis of a size of cumulative share price changes determining the interval span for state assignment again as a multiple of standard deviation of daily share price change. In such defined state space there are states in which a trend change occurs with a sufficiently high level of probability. This third approach is used in our research.

\section{Data and Methodology}

In this part of the paper we will first characterize the data on which the research is carried on and then we will describe the procedure of state space modelling and we will explain the principle of trading strategy.

\subsection{Data}

The research is based on the data from the Czech stock market. We received the share prices of three companies traded at Prague Stock Exchange. These companies are Telefónica O2, Komerční banka and ČEZ (O2, KB and CEZ). We have to our disposal daily opening and closing prices for each company in the period of seven years, from $5^{\text {th }}$ January 2006 until $2^{\text {nd }}$ January 2013 , i.e. ca. 1,760 trading days. The development of monitored shares value including paid out net dividends can be seen in Fig.1.

\section{Fig. 1: Shares value development}

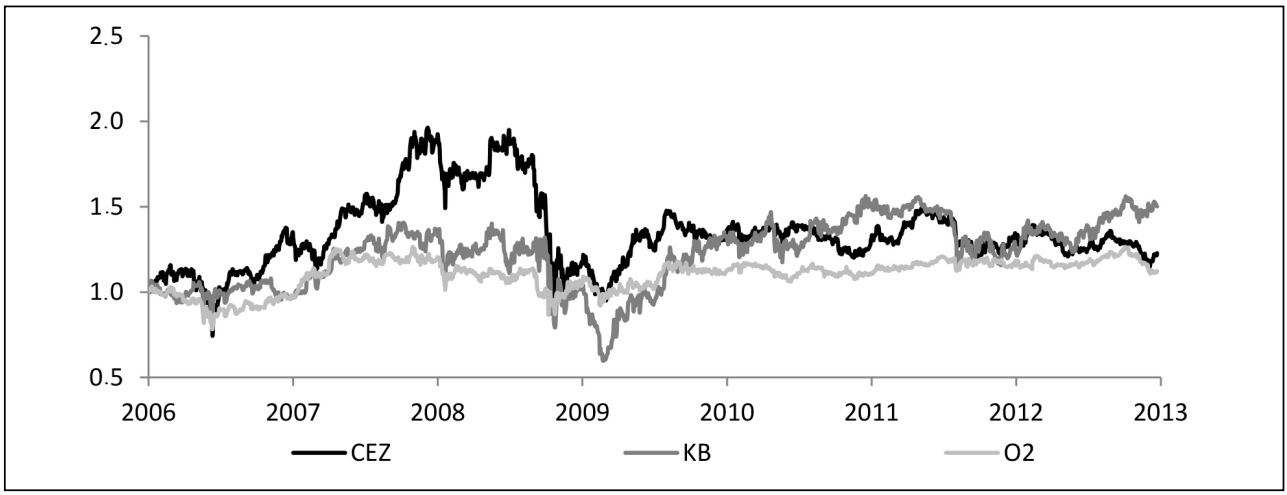

Source: Patria, author

It is seen in the chart that during the seven years long period shares of monitored companies went through all the three types of primary trend but each company with a different intensity. We can observe a growing trend in the years 2006 to 2007, a decreasing trend with a follow-up partial correction in the years 2008 and 2009 and a sideway trend which comes after the year 2010 .

\subsection{State Space}

We define a state space out of cumulative daily share price changes. A cumulative share price change is denoted $Y_{t},\left(y_{t}\right.$ is $Y_{t}$ expressed as a percentage). $Y_{t}$ is interpreted as short basis indexes of daily closing prices, being the basic period the day of trend change, i.e. the transition from a decrease to a growth or vice versa. The length of the time period is determined by the number of growing or decreasing closing prices in sequence. $Y_{t}$ is calculated according to the following relations:

$$
\begin{aligned}
& Y_{t}=Y_{t-1} \frac{P_{t}}{P_{t-1}} \text { if }\left(P_{t-2} \leq P_{t-1} \leq P_{t}\right) \\
& \operatorname{or}\left(P_{t-2} \geq P_{t-1} \geq P_{t}\right), \\
& Y_{t}=\frac{P_{t}}{P_{t-1}} \text { otherwise, }
\end{aligned}
$$


where $P_{t}$ is daily closing price in time $t, P_{t-1}$ is daily closing price in time $t-1$ and $P_{t-2}$ is daily closing price in time $t-2$. We define a state space on values $y_{t}$. We will use a set of eight states to sort out the data. The states when the share price decreases will be denoted $D_{i}$. The state $D_{1}$ will be the state with the lowest price decrease and on the contrary the state $D_{4}$ will denote the state with the highest price decrease. States when the share price grows will be denoted $G_{i}$. The state $G_{1}$ will be the state with the lowest price growth and $G_{4}$ will denote the state with the highest price growth. A common state space model will be defined on the following principle:

$$
\begin{array}{lc}
\mathrm{D}_{4}: y_{\mathrm{t}}<-3 \Delta ; & \mathrm{D}_{3}:-3 \Delta \leq y_{\mathrm{t}}<-2 \Delta ; \\
\mathrm{G}_{1}: 0 \leq y_{\mathrm{t}}<1 \Delta ; & \mathrm{G}_{2}: 1 \Delta \leq y_{\mathrm{t}}<2 \Delta ; \\
\mathrm{D}_{2}:-2 \Delta \leq y_{\mathrm{t}}<-1 \Delta ; & \mathrm{D}_{1}:-1 \Delta \leq y_{\mathrm{t}}<0 \\
\mathrm{G}_{3}: 2 \Delta \leq y_{\mathrm{t}}<3 \Delta ; & \mathrm{G}_{4}: 3 \Delta \leq y_{\mathrm{t}}
\end{array}
$$

where $\Delta=k \sigma, \sigma$ is a standard deviation of daily share price changes and $k$ is a multiple of a standard deviation. For particular shares the standard deviation value is as follows: $\sigma_{\mathrm{O} 2}=$ $1.442 \%, \sigma_{\mathrm{CEZ}}=1.996 \%, \sigma_{\mathrm{KB}}=2.355 \%$. The procedure used for sorting out the states is illustrated in Tab.1.
We will perform a filtration on the obtained MC. A filtration is understood as omitting the subsequent identical states. In this way we leave out the states where the share price stagnates (or more precisely, it changes only very little in the same trend). These states are not interesting for us from the trading point of view. To illustrate this, we can show a part of chain before the filtration: ... $D_{4}, G_{1}, G_{1}, G_{1}, G_{2}$, $D_{1}, D_{1}, D_{2}, G_{2}, D_{2}, D_{2}, \ldots$ and after the filtration: $\ldots D_{4}, G_{1}, G_{2}, D_{1}, D_{2}, G_{2}, D_{2}, \ldots$. We will determine the transition probability matrix $P$ for the after-filtered MC. Transition probabilities for the model $k=1$ are shown in Tab. 2. Discovered probabilities are displayed only with three decimals, therefore the probabilities sum does not have to equal 1 precisely. Direct transitions among some states are impossible and in these impossible transitions there is null without decimals. The columns $\Sigma G_{i}$ and $\Sigma D_{i}$ quote the probability of remaining in a trend or a change in a trend. For example, we can observe that if the $\mathrm{KB}$ share is now in the state $D_{3}$, the probability of a trend change is 0.742 and the probability of continuing in a decreasing trend is 0.258 . In the last column there is a number of particular states incidence stated.

The results in Tab. 2 show that we got a principle for modelling a state space with such

\section{Tab. 1: Procedure of model illustration for CEZ shares and $k=0.5(\Delta=0.998)$}

\begin{tabular}{c|c|c|c|c|c|c|c|c|c}
$\boldsymbol{t}$ & $\mathbf{1}$ & $\mathbf{2}$ & $\mathbf{3}$ & $\mathbf{4}$ & $\mathbf{5}$ & $\mathbf{6}$ & $\mathbf{7}$ & $\mathbf{8}$ & $\mathbf{9}$ \\
\hline$P_{t}$ & 801.2 & 809.0 & 813.7 & 807.5 & 802.1 & 819.0 & 825.0 & 834.0 & 821.0 \\
\hline$Y_{t}$ & & 1.0097 & 1.0156 & 0.9924 & 0.9857 & 1.0211 & 1.0286 & 1.0398 & 0.9844 \\
\hline$y_{t}$ & & $0.97 \%$ & $1.56 \%$ & $-0.76 \%$ & $-1.43 \%$ & $2.11 \%$ & $2.86 \%$ & $3.98 \%$ & $-1.56 \%$ \\
\hline state & & $\mathrm{G}_{1}$ & $\mathrm{G}_{2}$ & $\mathrm{D}_{1}$ & $\mathrm{D}_{2}$ & $\mathrm{G}_{3}$ & $\mathrm{G}_{3}$ & $\mathrm{G}_{4}$ & $\mathrm{D}_{2}$ \\
\hline
\end{tabular}

states where a trend change occurs very likely. We are going to use this principle of state space definition for creating trading strategies.

\subsection{Trading Strategies}

Trading strategies are created on the following principle. When a certain level of a share price decrease is reached, a buying signal is generated and when a certain level of a share price growth is reached, a selling signal is generated. Trading strategies are always realized according to the rules as follows. One trade (transaction) is understood as a share buying and a following selling. If a buying or selling signal is generated one day, the trade is realized for the opening price from the following day. The whole capital is always invested (it means that it is theoretically possible to buy a part of a share). We do not take into consideration any transaction fees. We count and reinvest paid out dividends after tax in case that we obtained shares on the record day. 
Tab. 2: Transition probabilities for the model $k=1$

\begin{tabular}{|c|c|c|c|c|c|c|c|c|c|c|c|c|}
\hline \multicolumn{2}{|c|}{$n-1{ }^{n}$} & $\mathrm{D}_{4}$ & $\mathrm{D}_{3}$ & $\mathrm{D}_{2}$ & $D_{1}$ & $\mathbf{G}_{1}$ & $\mathbf{G}_{2}$ & $\mathbf{G}_{3}$ & $\mathbf{G}_{4}$ & $\sum D_{i}$ & $\sum G_{i}$ & $n$ \\
\hline \multirow[t]{3}{*}{$D_{4}$} & 02 & 0 & 0 & 0 & 0 & 0.475 & 0.375 & 0.025 & 0.125 & 0 & 1 & 40 \\
\hline & CEZ & 0 & 0 & 0 & 0 & 0.282 & 0.564 & 0.051 & 0.103 & 0 & 1 & 39 \\
\hline & KB & 0 & 0 & 0 & 0 & 0.457 & 0.229 & 0.229 & 0.086 & 0 & 1 & 35 \\
\hline \multirow[t]{3}{*}{$D_{3}$} & 02 & 0.358 & 0 & 0 & 0 & 0.448 & 0.179 & 0.015 & 0.000 & 0.358 & 0.642 & 67 \\
\hline & CEZ & 0.333 & 0 & 0 & 0 & 0.439 & 0.193 & 0.035 & 0.000 & 0.333 & 0.667 & 57 \\
\hline & KB & 0.258 & 0 & 0 & 0 & 0.485 & 0.152 & 0.091 & 0.015 & 0.258 & 0.742 & 66 \\
\hline \multirow[t]{3}{*}{$D_{2}$} & 02 & 0.065 & 0.258 & 0 & 0 & 0.497 & 0.142 & 0.032 & 0.006 & 0.323 & 0.677 & 155 \\
\hline & CEZ & 0.079 & 0.220 & 0 & 0 & 0.567 & 0.110 & 0.018 & 0.006 & 0.299 & 0.701 & 164 \\
\hline & KB & 0.079 & 0.287 & 0 & 0 & 0.500 & 0.091 & 0.037 & 0.006 & 0.366 & 0.634 & 164 \\
\hline \multirow[t]{3}{*}{$D_{1}$} & 02 & 0.006 & 0.047 & 0.261 & 0 & 0.584 & 0.094 & 0.009 & 0.000 & 0.314 & 0.686 & 341 \\
\hline & CEZ & 0.006 & 0.029 & 0.266 & 0 & 0.622 & 0.072 & 0.003 & 0.003 & 0.301 & 0.699 & 349 \\
\hline & KB & 0.009 & 0.043 & 0.272 & 0 & 0.568 & 0.084 & 0.014 & 0.009 & 0.325 & 0.675 & 345 \\
\hline \multirow[t]{3}{*}{$\mathrm{G}_{1}$} & 02 & 0.012 & 0.006 & 0.089 & 0.567 & 0 & 0.282 & 0.034 & 0.009 & 0.675 & 0.325 & 326 \\
\hline & CEZ & 0.003 & 0.017 & 0.078 & 0.543 & 0 & 0.309 & 0.038 & 0.012 & 0.642 & 0.358 & 346 \\
\hline & KB & 0.003 & 0.000 & 0.092 & 0.593 & 0 & 0.260 & 0.031 & 0.021 & 0.688 & 0.312 & 327 \\
\hline \multirow[t]{3}{*}{$\mathrm{G}_{2}$} & 02 & 0.000 & 0.012 & 0.110 & 0.497 & 0 & 0 & 0.312 & 0.069 & 0.618 & 0.382 & 173 \\
\hline & CEZ & 0.005 & 0.005 & 0.109 & 0.552 & 0 & 0 & 0.262 & 0.066 & 0.672 & 0.328 & 183 \\
\hline & KB & 0.007 & 0.000 & 0.116 & 0.527 & 0 & 0 & 0.288 & 0.062 & 0.651 & 0.349 & 146 \\
\hline \multirow[t]{3}{*}{$\mathrm{G}_{3}$} & 02 & 0.000 & 0.027 & 0.080 & 0.587 & 0 & 0 & 0 & 0.307 & 0.693 & 0.307 & 75 \\
\hline & CEZ & 0.014 & 0.029 & 0.087 & 0.536 & 0 & 0 & 0 & 0.333 & 0.667 & 0.333 & 69 \\
\hline & KB & 0.000 & 0.013 & 0.143 & 0.532 & 0 & 0 & 0 & 0.312 & 0.688 & 0.312 & 77 \\
\hline \multirow[t]{3}{*}{$\mathrm{G}_{4}$} & 02 & 0.000 & 0.116 & 0.279 & 0.605 & 0 & 0 & 0 & 0 & 1 & 0 & 43 \\
\hline & CEZ & 0.044 & 0.044 & 0.400 & 0.511 & 0 & 0 & 0 & 0 & 1 & 0 & 45 \\
\hline & KB & 0.000 & 0.063 & 0.250 & 0.688 & 0 & 0 & 0 & 0 & 1 & 0 & 48 \\
\hline
\end{tabular}

Dividends are included in the moment of share selling. A short selling is not taken into account and two consecutive buyings are not possible. The invested capital value is calculated according to the following relation:

$$
C_{i}=C_{i-1} \frac{S_{i}+D_{i}}{B_{i}}
$$

and after $n^{\text {th }}$ trades (transactions) the capital value will be:

$$
C_{n}=C_{0} \prod_{i=1}^{n} \frac{S_{i}+D_{i}}{B_{i}}
$$

where $C_{0}=1.000$ is initial capital value, $C_{n}$ is capital value after the $n_{\text {th }}$ transaction, $S_{i}$ is selling price in the $i_{\text {th }}$ transaction, $D_{i}$ are dividends after tax in case that during the $i_{\text {th }}$ transaction there was a record day, $B_{i}$ is buying price in the $i_{\text {th }}$ transaction .

We will compare the profit brought by the trading strategy with the profit we would 
reach by the passive strategy "buy and hold" (i.e. shares are bought and then only held, not traded). Reached profitability of particular shares with the strategy "buy and hold" in the studied period is for O2 shares 1.122, CEZ shares 1.227 and for KB shares 1.502. In case of portfolio investing, it means that investment is distributed equally among all three shares, profitability of this portfolio is 1.284 .

\section{Results and Discussion}

We will gradually test the trading strategies on 14 state space models. A model is determined by the value $k$, where $k$ will gradually acquire values from 0.5 to 1.8 , with one step being 0.1 (for $k<0.5$ trades are concentrated on the states $D_{3}, D_{4}$ and $G_{3}, G_{4}$; for $k>1.8$ the states $D_{3}, D_{4}$ and $G_{3}, G_{4}$ are found only very few times). For each model we will calculate nine $(3 \times 3)$ trading strategies. States $D_{2}, D_{3}, D_{4}$ will generate a buying signal and states $G_{2}$, $G_{3}, G_{4}$ selling signals. States $D_{1}$ and $G_{1}$ are not used for states generating because we require a minimal share price decrease and growth.

First we will present all trading strategies profitability on two models $(\mathrm{k}=0.5$ and $\mathrm{k}=1.8)$. For other models only summary results will be presented. Finally we will calculate the strategies profitability in case of investments into shares portfolio. We will always give short comments to the presented results.

\subsection{Profitability of Chosen Models}

The first calculated model is the model with $k=0.5$. A state space is defined as follows:

$$
\begin{array}{ll}
\mathrm{D}_{4}: y_{\mathrm{t}}<-1.5 \sigma ; & \mathrm{D}_{3}:-1.5 \sigma \leq y_{\mathrm{t}}<-1.0 \sigma ; \\
\mathrm{G}_{1}: 0 \leq y_{\mathrm{t}}<0.5 \sigma ; & \mathrm{G}_{2}: 0.5 \sigma \leq y_{\mathrm{t}}<1.0 \sigma ; \\
\mathrm{D}_{2}:-1.0 \sigma \leq y_{\mathrm{t}}<-0.5 \sigma ; & \mathrm{D}_{1}:-0.5 \sigma \leq y_{\mathrm{t}}<0 \\
\mathrm{G}_{3}: 1.0 \sigma \leq y_{\mathrm{t}}<1.5 \sigma ; & \mathrm{G}_{4}: 1.5 \sigma \leq y_{\mathrm{t}} .
\end{array}
$$

The obtained profitability of particular trading strategies and the number of realized trades can be seen in Tab. 3. Trading strategies which reached a higher profitability than the strategy "buy and hold" are highlighted in this and in the other tables with bold font.

The results show that in case of $\mathrm{O} 2$ shares six strategies beat the strategy "buy and hold" (success rate $66.7 \%$ ), in case of CEZ shares four strategies were the winning ones $(44.4 \%)$ and in case of $K B$ shares four strategies beat it as well $(44.4 \%)$. The number of realized trades was between 63 and 113 . We may state that the strategies with states $D_{2}$ and $G_{2}$ were only little successful, the trading strategy $D_{2}-G_{2}$ did not even beat the strategy "buy and hold" in

\begin{tabular}{|c|c|c|c|c|c|c|c|}
\hline \multirow{2}{*}{ buy } & & \multicolumn{2}{|c|}{$\mathbf{G}_{2}$} & \multicolumn{2}{|c|}{$\mathbf{G}_{3}$} & \multicolumn{2}{|c|}{$\mathbf{G}_{4}$} \\
\hline & & $C_{n}$ & $n$ & $C_{n}$ & $n$ & $C_{n}$ & $n$ \\
\hline \multirow{3}{*}{$\mathrm{D}_{2}$} & $\mathrm{O} 2$ & 0.977 & 107 & 0.764 & 84 & 1.048 & 94 \\
\hline & CEZ & 0.890 & 113 & 1.183 & 88 & 1.213 & 82 \\
\hline & KB & 0.909 & 105 & 2.017 & 81 & 1.028 & 88 \\
\hline \multirow{3}{*}{$\mathrm{D}_{3}$} & $\mathrm{O} 2$ & 1.608 & 72 & 1.434 & 63 & 1.511 & 65 \\
\hline & CEZ & 1.119 & 78 & 1.899 & 69 & 2.084 & 81 \\
\hline & KB & 0.681 & 77 & 1.373 & 65 & 1.691 & 72 \\
\hline \multirow{3}{*}{$D_{4}$} & $\mathrm{O} 2$ & 1.986 & 77 & 1.295 & 74 & 1.619 & 87 \\
\hline & CEZ & 1.189 & 76 & 1.803 & 75 & 2.335 & 93 \\
\hline & KB & 1.604 & 79 & 1.281 & 66 & 2.156 & 91 \\
\hline
\end{tabular}
case of any share. The strategies $D_{4}$ and $G_{4}$ were successful, the strategy $G_{4}-D_{4}$ highly beat the strategy "buy and hold" in all cases of the three shares. We must also pay attention to the fact that a small change of trading strategy parameter (neighbouring strategy) can bring very different results. For example, in case 
of $\mathrm{KB}$ there is a big difference in profitability among strategies with a buying signal $D_{2}$.

We can expect that in other models with the increasing $k$ the success rate of strategies with states $D_{2}$ and $G_{2}$ will grow and the number of trades will decrease. This expectation is confirmed in Tab. 4 where detailed results for the model $k=1.8$ are given.

The model $k=1.8$ is the last one that was calculated. Although the model reached a good profitability, we would need to realize more trades to confirm strategies success and thus to study a longer period of time than the one we have at our disposal. It still holds true that a small change of a trade strategy parameter can bring very different results. We can see it for example in $K B$ for strategies $D_{3}-G_{2}$ and $D_{4}-G_{2}$. Models with $k>1.8$ were not calculated because the realized trades number was very low.

We will not present such detailed results for other models. We will present only summary results for each model.

\subsection{Summary Results}

Summary results for particular models are presented in Tab. 5. The table shows winning strategies proportion for each model and each share and also reached average profitability for each share which is calculated according to the formula:

$$
\bar{C}=\frac{C_{D_{2}-G_{2}}+C_{D_{2}-G_{3}}+\ldots+C_{D_{4}-G_{4}}}{9}
$$

In the penultimate column the average profitability for the whole model is stated. It is calculated according to the relation:

$$
\overline{\bar{C}}=\frac{\bar{C}_{O 2}+\bar{C}_{C E Z}+\bar{C}_{K B}}{3}
$$

The total number of trades realized in the stated model is given in the last column of this table (27 trading strategies).

We can see in the table that most of the trading strategies beat the passive strategy "buy and hold". From the point of view of particular models it may be stated that the average model profit for models $\mathrm{k} \geq 0.7$ was always higher than 1.5 , by which the average profit of the "buy and hold" strategy, 1.284, was considerably overcome. Models $0.8 \leq k \leq 1.2$ and $k \geq 1.5$ reach the highest profits.

When taking into consideration only models $k \geq 0.7$, from the point of view of particular shares $\mathrm{O} 2$, the shares showed the best performance for these models. Winning strategies ratio for no model was lower than 0.778 and average strategies profitability in the portfolio was always higher than the profitability obtained by passive share holding. Also CEZ shares showed a good performance, the winning strategies ratio was never lower than 0.556 and the average profitability was always higher than the one by the passive share holding. With KB shares the winning strategies ratio was about 0.5 and in three models $(k=1.1 ; 1.3 ; 1.4)$ the

Tab. 4:

\begin{tabular}{|c|c|c|c|c|c|c|c|}
\hline \multirow{2}{*}{ buy } & \multirow[t]{2}{*}{ sell } & \multicolumn{2}{|c|}{$\mathbf{G}_{2}$} & \multicolumn{2}{|c|}{$\mathbf{G}_{3}$} & \multicolumn{2}{|c|}{$\mathbf{G}_{4}$} \\
\hline & & $C_{n}$ & $n$ & $C_{n}$ & $\mathbf{n}$ & $C_{n}$ & $\mathrm{n}$ \\
\hline \multirow{3}{*}{$\mathrm{D}_{2}$} & $\mathrm{O} 2$ & 2.114 & 63 & 1.895 & 23 & 1.540 & 11 \\
\hline & CEZ & 1.451 & 56 & 1.577 & 20 & 1.510 & 9 \\
\hline & KB & 2.542 & 69 & 1.414 & 25 & 1.574 & 18 \\
\hline \multirow{3}{*}{$D_{3}$} & $\mathrm{O} 2$ & 1.264 & 20 & 1.688 & 13 & 1.376 & 8 \\
\hline & CEZ & 1.367 & 18 & 1.016 & 8 & 1.320 & 6 \\
\hline & KB & 1.013 & 19 & 0.837 & 13 & 1.383 & 13 \\
\hline \multirow{3}{*}{$D_{4}$} & $\mathrm{O} 2$ & 1.880 & 9 & 1.520 & 6 & 1.437 & 7 \\
\hline & CEZ & 1.704 & 9 & 1.241 & 6 & 2.402 & 7 \\
\hline & KB & 2.725 & 14 & 1.451 & 11 & 2.053 & 11 \\
\hline
\end{tabular}

Results of model $k=1.8$ 


\begin{tabular}{|c|c|c|c|c|c|c|c|c|}
\hline Tab. 5: & Summa & sults & & & & & & \\
\hline \multirow{2}{*}{$\boldsymbol{k}$} & \multicolumn{3}{|c|}{ winning strategies proportion } & \multicolumn{3}{|c|}{ portfolio value $-\bar{C}$} & \multirow{2}{*}{$\overline{\bar{C}}$} & \multirow{2}{*}{$\sum_{i=1}^{3} \sum_{j=1}^{9} n_{i, j}$} \\
\hline & $\mathbf{0 2}$ & CEZ & KB & $\mathbf{0 2}$ & CEZ & KB & & \\
\hline 0.5 & 0.667 & 0.444 & 0.444 & 1.360 & 1.524 & 1.416 & 1.433 & 2,202 \\
\hline 0.6 & 0.778 & 0.778 & 0.222 & 1.425 & 1.472 & 1.344 & 1.414 & 2,007 \\
\hline 0.7 & 0.889 & 0.556 & 0.444 & 1.558 & 1.425 & 1.548 & 1.510 & 1,819 \\
\hline 0.8 & 0.778 & 0.778 & 0.556 & 1.731 & 1.423 & 1.882 & 1.679 & 1,639 \\
\hline 0.9 & 0.889 & 0.667 & 0.667 & 1.695 & 1.393 & 1.642 & 1.577 & 1,404 \\
\hline 1.0 & 1.000 & 0.667 & 0.556 & 1.662 & 1.734 & 1.743 & 1.713 & 1,220 \\
\hline 1.1 & 1.000 & 0.667 & 0.444 & 1.423 & 1.706 & 1.442 & 1.524 & 1,067 \\
\hline 1.2 & 1.000 & 0.667 & 0.444 & 1.632 & 1.558 & 1.576 & 1.589 & 935 \\
\hline 1.3 & 0.889 & 0.778 & 0.444 & 1.607 & 1.505 & 1.449 & 1.520 & 810 \\
\hline 1.4 & 1.000 & 0.667 & 0.444 & 1.754 & 1.368 & 1.387 & 1.503 & 711 \\
\hline 1.5 & 1.000 & 0.667 & 0.778 & 1.694 & 1.404 & 1.598 & 1.565 & 644 \\
\hline 1.6 & 1.000 & 0.556 & 0.667 & 1.552 & 1.455 & 1.677 & 1.561 & 576 \\
\hline 1.7 & 1.000 & 1.000 & 0.778 & 1.694 & 1.580 & 1.783 & 1.686 & 581 \\
\hline 1.8 & 1.000 & 0.889 & 0.444 & 1.635 & 1.510 & 1.666 & 1.603 & 492 \\
\hline
\end{tabular}

Source: author's calculation

portfolio did not reach the profit of the passive strategy "buy and hold".

\subsection{Profitability of Shares Portfolio}

The results presented above show that there are strategies which do not overcome the market. These strategies cannot be identified in advance. One of the possibilities how to reduce a risk in the stock market is capital investing into more shares, it means creating a shares portfolio. Therefore we will divide the invested capital equally into three analysed shares and we will calculate the profitability of this portfolio.

We will calculate the profitability only for the most successful models with a sufficient number of trades. It means for the models $0.8 \leq \mathrm{k} \leq 1.2$. The models with $k \geq 1.5$ have a low number of trades and they will be a subject of another separate research. In the studied portfolios we are interested in obtained capital value and in the average number of trades,

$$
\begin{aligned}
\bar{C}_{D_{i}-G_{j}}= & \frac{C_{O 2, D_{i}-G_{j}}+C_{\mathrm{CEZ}, D_{i}-G_{j}}+C_{\mathrm{KB}, D_{i}-G_{j}}}{3}, \\
\bar{n}_{D_{i}-G_{j}} & =\frac{n_{O 2, D_{i}-G_{j}}+n_{\mathrm{CEZ}, D_{i}-G_{j}}+n_{\mathrm{KB}, D_{i}-G_{j}}}{3} .
\end{aligned}
$$

The results are stated in Tab 6.

The results show that all portfolios with selling signals $G_{3}$ and $G_{4}$ overcame the value of passive portfolio "buy and hold" $(1,284)$. One important question for us is how the portfolio value develops in time. The development of chosen portfolios value is seen in Fig. 2. To make it clear we chose only four portfolios. If we had chosen more strategies, the figure would have been too unclear. The portfolio of the trading strategy $D_{4}-G_{4}$ was chosen for the model $k=0.8$, for the model $k=1.0$ two strategies $D_{4}-G_{3}$ and $D_{3}-G_{4}$ and for the model $k=1.2$ the strategy $D_{3}-G_{3}$ was chosen.

The chart offers valuable information. We can see that in the market growth period, years 2006, 2007 and a part of the year 2009, trading strategies were copying or losing in comparison with the passive portfolio "buy and hold". In contrast, in the market decrease period, the second half of the year 2008 and the beginning of the year 2009, trading strategies were making smaller loss or were showing stagnation. In the period of sideway trend, from the year 2010 , all portfolios reached higher profits than the passive portfolio. 


\section{Finance}

\begin{tabular}{|c|c|c|c|c|c|c|c|}
\hline \multirow{2}{*}{$k$} & & & & & & & \\
\hline & buy & $\bar{C}$ & $\bar{n}$ & $\bar{C}$ & $\bar{n}$ & $\bar{C}$ & $\bar{n}$ \\
\hline \multirow{3}{*}{0.8} & D2 & 1.101 & 112.3 & 1.687 & 74.3 & 1.740 & 58.0 \\
\hline & D3 & 1.248 & 70.7 & 1.734 & 55.0 & 2.014 & 49.3 \\
\hline & D4 & 1.290 & 44.7 & 1.661 & 40.3 & 2.635 & 41.7 \\
\hline \multirow{3}{*}{0.9} & D2 & 1.277 & 113.0 & 1.405 & 63.7 & 1.725 & 47.0 \\
\hline & D3 & 1.443 & 61.3 & 1.667 & 47.3 & 1.769 & 39.0 \\
\hline & D4 & 1.306 & 36.3 & 1.571 & 30.3 & 2.027 & 30.0 \\
\hline \multirow{3}{*}{1.0} & D2 & 1.706 & 105.3 & 1.931 & 60.7 & 1.752 & 37.0 \\
\hline & D3 & 1.213 & 51.3 & 2.076 & 43.0 & 1.630 & 28.3 \\
\hline & D4 & 1.250 & 30.3 & 1.952 & 27.0 & 1.905 & 23.7 \\
\hline \multirow{3}{*}{1.1} & D2 & 1.625 & 102.7 & 1.871 & 53.7 & 1.739 & 32.3 \\
\hline & D3 & 1.115 & 44.3 & 1.382 & 34.0 & 1.506 & 23.7 \\
\hline & D4 & 1.204 & 24.7 & 1.817 & 22.0 & 1.453 & 18.3 \\
\hline \multirow{3}{*}{1.2} & D2 & 1.319 & 93.0 & 1.938 & 50.3 & 1.465 & 26.0 \\
\hline & D3 & 1.084 & 37.3 & 2.081 & 30.3 & 2.039 & 20.3 \\
\hline & D4 & 1.144 & 20.0 & 1.825 & 18.7 & 1.404 & 15.7 \\
\hline
\end{tabular}

Source: author's calculation

\section{Fig. 2: Development of capital value}

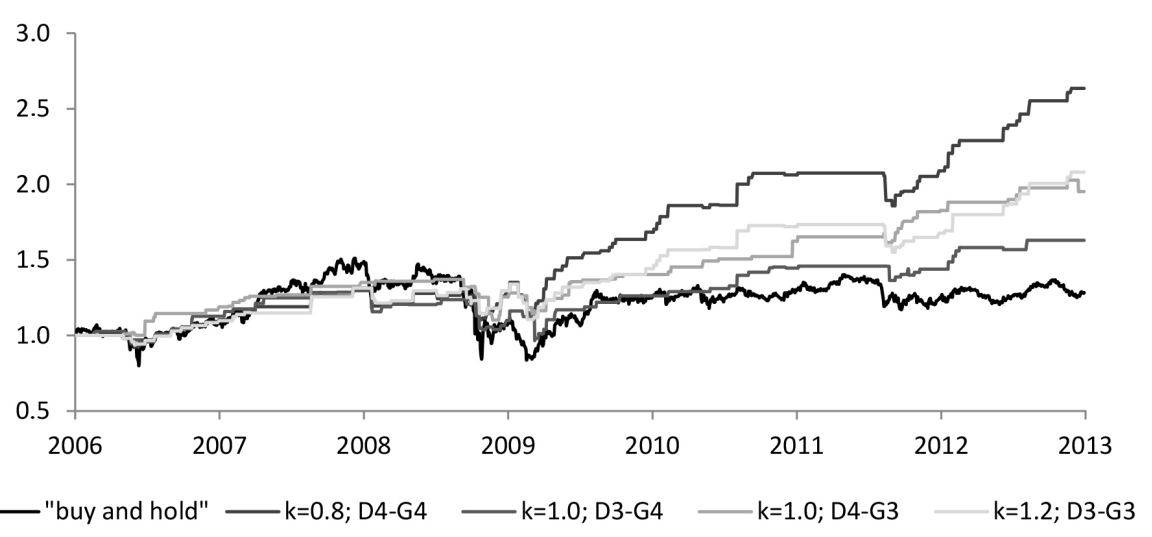




\section{Tab. 7: Annual yield of portfolios}

\begin{tabular}{c|c|c|c|c|c|c|c|c|c|c}
\multirow{2}{*}{ year } & \multicolumn{2}{|c|}{ buy and hold } & \multicolumn{2}{|c|}{$\mathbf{k = 0 . 8} \mathbf{D}_{\mathbf{4}}-\mathbf{G}_{\mathbf{4}}$} & \multicolumn{2}{c|}{$\mathbf{k = 1 . 0} ; \mathbf{D}_{\mathbf{3}}-\mathbf{G}_{\mathbf{4}}$} & \multicolumn{2}{|c|}{$\mathbf{k = 1 . 0} ; \mathbf{D}_{\mathbf{4}}-\mathbf{G}_{\mathbf{3}}$} & \multicolumn{2}{|c}{$\mathbf{k = 1 . 2} ; \mathbf{D}_{\mathbf{3}}-\mathbf{G}_{\mathbf{3}}$} \\
\cline { 2 - 12 } & $\mathbf{C}$ & yield & $\mathbf{C}$ & yield & $\mathbf{C}$ & yield & $\mathbf{C}$ & yield & $\mathbf{C}$ & yield \\
\hline 2012 & 1.284 & $2.7 \%$ & 2.635 & $26.1 \%$ & 1.630 & $13.3 \%$ & 1.952 & $6.9 \%$ & 2.081 & $24.1 \%$ \\
\hline 2011 & 1.250 & $-3.2 \%$ & 2.089 & $1.3 \%$ & 1.439 & $-0.5 \%$ & 1.827 & $12.5 \%$ & 1.677 & $-2.5 \%$ \\
\hline 2010 & 1.292 & $3.6 \%$ & 2.062 & $22.5 \%$ & 1.446 & $14.6 \%$ & 1.623 & $15.7 \%$ & 1.720 & $19.3 \%$ \\
\hline 2009 & 1.247 & $16.8 \%$ & 1.683 & $31.1 \%$ & 1.262 & $14.8 \%$ & 1.403 & $11.8 \%$ & 1.441 & $11.3 \%$ \\
\hline 2008 & 1.068 & $-27.7 \%$ & 1.284 & $-2.3 \%$ & 1.099 & $-15.2 \%$ & 1.254 & $-7.1 \%$ & 1.296 & $-1.3 \%$ \\
\hline 2007 & 1.477 & $36.4 \%$ & 1.314 & $20.4 \%$ & 1.296 & $15.0 \%$ & 1.351 & $15.6 \%$ & 1.313 & $21.1 \%$ \\
\hline 2006 & 1.082 & $8.2 \%$ & 1.091 & $9.1 \%$ & 1.127 & $12.7 \%$ & 1.168 & $16.8 \%$ & 1.084 & $8.4 \%$ \\
\hline
\end{tabular}

Source: author's calculation

Let's have a look at annual yield in particular years. These yields are shown in Tab. 7 . They are approximate annual yields because portfolios are not appraised every day but only on the day of share sale. It means that if we hold shares at the end of the year, the given portfolio value is the same as the value in time of the last sale. The only exception is the value on $28^{\text {th }}$ December 2012 when in case we had bought some shares, these shares were appraised with the closing price of this day.

Annual yields confirm that the only year in which the strategy "buy and hold" beat the trading strategies, was the year 2007 when the "buy and hold" strategy reached the yield $36.4 \%$. In other years our trading strategies were doing better or comparably.

The differences among profitability will become even more apparent if we have a look at average annual yields. Average annual yield is calculated as geometric mean. The average annual yield of the strategy "buy and hold" was $3.6 \%$. The average yield for portfolios calculated in Tab. 6 with the selling signals in $\mathrm{G}_{3}$ or $\mathrm{G}_{4}$ oscillates between $4.7 \%\left(k=1.1 ; \mathrm{D}_{3}-\mathrm{G}_{3}\right)^{3}$ and $14.8 \%\left(k=0.8 D_{4}-G_{4}\right)$.

From the point of view of practical use we have to take into consideration transaction costs (fees). Costs are usually determined by the percentage from the trade volume. When calculating the costs, the invested capital value after $n$ - trade transactions may be approximately determined according to the relation:

$$
C_{\text {after fees }}=C_{n}\left(\frac{1-\frac{p}{100}}{1+\frac{p}{100}}\right)^{n} \text {, }
$$

where $p$ is the fee in percent. When trading orders are submitted electronically, the lowest fees are around $0.1 \%$ from the trade volume. It is seen in Tab. 6 that the average number of realized trades for the strategies $G_{3}$ and $G_{4}$ was between $15.7\left(k=0.8 D_{4}-G_{4}\right)$ and 74.3 $\left(k=0.8 D_{2}-G_{3}\right)$. With substitution to the relation 9 and with the fee $0.1 \%$ we will find out that lowering average annual yields would occur approximately in the range from 0.45 to 2.1 percentage points.

\section{Conclusions}

Our intention was to create a stochastic model which will successfully predict a short term share price movement and which will be usable for generating trading signals. Trading, according to these signals, should bring higher profitability than passive share holding. The presented results show that the aim was reached. Applying the Markov chain theory we found a compact set of state space models $0.8 \leq k \leq 1.2$ and on the basis of this set of models we defined a compact set of trading strategies $\left(D_{2}, D_{3}, D_{4}\right) \times\left(G_{3}, G_{4}\right)$ which beat the passive strategy "buy and hold". The strategy "buy and hold" is beaten even after including transaction costs, which is important in case of practical application in algorithmic trading systems. The results are even more 
encouraging as it is a case of basic onecriterion model with stationary strategy which for example does not take into consideration the changing volatility of stock markets. This is probably the reason why we obtained the most stable results with $\mathrm{O} 2$ shares, which had the lowest volatility in the studied period.

The obtained results are also a contribution to the discussion about the efficiency of Czech stock market. The results point out ineffective behaviour of Czech stock market and thus they do not confirm the conclusions of works Diviš and Teplý (2005) or Hájek (2005) about increasing efficiency of Czech stock market. On the contrary, the results confirm the conclusions of work Svoboda and Říhová (2015) which states that Czech stock market is not able to absorb unexpected information quickly and precisely. They also support the Overreactions Theory (De Bond \& Thaler, 1994) according to which share prices overvalue (undervalue) the right values after releasing new information and therefore their backward movement must come.

We will continue with the research, we think that we may reach even higher profitability by modifying this basic trading strategy. Our next research will concentrate on the following fields:

- Confirmation of this work results which means including other shares into portfolios and also prolongation of the time period.

- More detailed analysis of trading strategies success in growing, decreasing and sideway primary trend.

- Development of a dynamic model which would react to changing volatility in stock markets.

- Application of these models in other stock markets.

- Development of a more-criterion model which would for example change trading strategies depending on prediction of primary trend development. One strategy is more suitable for a growing primary trend and another for a sideway trend.

The article was supported by the motivation system of University of West Bohemia in Pilsen, part POSTDOC and is elaborated as one of the results of the research project "The Research of Factors Affecting Share Price Movement, Prediction of Share Price Movement and Design of Algorithms for Self-acting Trading" SGS-2015-026 of the Faculty of Economics, University of West Bohemia in Pilsen.

\section{References}

Brock, W., Lakonishok, J., \& LeBaron, B. (1992). Simple Technical Trading Rules and The Stochastic Properties of Stock Returns. Journal of Finance, 47(5), 1731-1764. doi:10.1111/j.1540-6261.1992.tb04681.x

Doubleday, K.J., \& Esunge, J.N. (2011). Application of Markov Chains to Stock Trends. Journal of Mathematics and Statistics, 7(2), 103-106.

De Bondt, W.F.M., \& Thaler, R.H. (1994). Financial decision - making in market and firms: a behavioral perspective (Working paper No. 4777). National Bureau of Economic Research. doi:10.3386/w4777.

Diviš, K., \& Teplý, P. (2005). Informační efektivnost burzovních trhů ve střední Evropě. Czech Journal of Economics and Finance, 55(9-10), 471-482.

Fama, E. (1970). Efficient Capital Markets: a Review of Theory and Empirical Work. The Journal of Finance, 25(2), 383-417. doi:10.1111/j.1540-6261.1970.tb00518.x.

Fama, E. (2005). The Behavior of Stock Market Prices. The Journal of Business, 38(1), 34-105.

Fama, E., \& Blume, M. (1966). Filter Rules and Stock-Market Trading. The Journal of Business, 39(1), 226-241.

Hájek, J. (2006). Slabá forma efektivnosti středoevropských akciových trhů (Doctoral dissertation). Retrieved from https://www.vse.cz.

Jensen, M.C., \& Benington, G.A. (1970). Random walks and technical theories: some additional evidence. The Journal of Finance, 25(2), 469-482. doi:10.1111/j.1540-6261.1970.tb00671.x.

Murphy, J. (1999). Technical analysis of the Financial markets. New York: Penguin Group.

Solnik, B. (1973). Note on the validity of the random walk for European stock prices. Journal of Finance 28(5), 1151-1159. doi:10.2307/2978754.

Svoboda, M., Lukáš, L. (2012). Application of Markov chain analysis to trend prediction of stock indices. In Proceedings of the 30th International Conference Mathematical Methods in Economics (pp. 848-853). Karviná: Silesian University in Opava.

Svoboda, M., Ríhová, P. (2015). Efficient Market Theory from the point of view of Markov chains analysis. In Proceedings of the 33th International Conference Mathematical Methods in Economics (pp. 772-776). Cheb: University of West Bohemia. 
Sweeny, R.J. (1988). Some new filter rule tests: methods and results. Journal of Financial and Quantitative Analysis, 23(3), 285-300. doi:10.2307/2331068.

Vasanthi, S., Subha, M.V., \& Nambi, S.T. (2011). An empirical Study on Stock Index trend prediction using Markov Chain analysis. JBFSIR, 1(1), 72-90.

Zhang, D., \& Zhang, X. (2009). Study on Forecasting the Stock Market Trend Based on Stochastic Analysis Method. International Journal of Business and Management, 4(6), 163-170. doi:10.5539/ijbm.v4n6p163.

Ing. Mgr. Milan Svoboda, Ph.D. University of West Bohemia Faculty of Economics Department of Economics and Quantitative Methods svobodm@kem.zcu.cz 


\section{Abstract}

\section{STOCHASTIC MODEL OF SHORT-TERM PREDICTION OF STOCK PRICES AND ITS PROFITABILITY IN THE CZECH STOCK MARKET}

\section{Milan Svoboda}

This paper deals with stochastic modelling and short time prediction of share price development in Czech stock market. The aim of this research is to create such models which can be used for creating automatic trading strategies that will beat the market. Reliability of these models is being checked in three highly liquid shares from Prague Stock O2, CEZ and KB in seven years long period in years 2006-2012. We used Markov chain analysis for modelling. In our models a state space is defined on the basis of cumulative daily changes of share price and a state space with eight states is used. The state space is defined parametrically as a multiple of standard deviation of daily yields for each share. There were 14 parameters calculated in total and for each parameter nine trading strategies for all shares were applied. It means that 378 trading strategies were calculated. We succeeded in finding a set of compact state space models and in applying a compact group of trading strategies on these models which always beat the market when invested in portfolio. The average annual market yield was $3.6 \%$. The average yield of our portfolios oscillates between $4.7 \%$ and $14.8 \%$. Strategies overcame the market also even after including transaction costs. After including transaction costs in amount of $0.1 \%$ from the trade volume a decrease of average annual yields would occur in the range from 0.45 to 2.1 percentage points. We reached the best results in the sideway trend and in shares with less changing volatility.

Conclusions of this research are in contradiction to the Efficient Market Hypothesis. Results indicate that Czech stock market is not effective in any of its form.

Key Words: Technical analysis indicators, stock market predication, trading strategies, Markov chain analysis, algorithmic trading.

JEL Classification: C02, C13, G14, G17.

DOI: 10.15240/tul/001/2016-2-013 